\title{
Regional scale analysis of the altimetric stream network evolution
}

\author{
T. Ghizzoni ${ }^{1}$, M. Lomazzi ${ }^{1}$, G. Roth $^{1,2}$, and R. Rudari ${ }^{1}$ \\ ${ }^{1}$ CIMA Centro di ricerca Interuniversitario in Monitoraggio Ambientale, Universities of Genoa and Basilicata, Italy \\ ${ }^{2}$ DIST, Dipartimento di Informatica, Sistemistica e Telematica, University of Genoa, Italy
}

Received: 9 November 2005 - Revised: 7 December 2005 - Accepted: 22 December 2005 - Published: 25 January 2006

\begin{abstract}
Floods result from the limited carrying capacity of stream channels when compared to the discharge peak value. The transit of flood waves - with the associated erosion and sedimentation processes - often modifies local stream geometry. In some cases this results in a reduction of the stream carrying capacity, and consequently in an enhancement of the flooding risk.

A mathematical model for the prediction of potential altimetric stream network evolution due to erosion and sedimentation processes is here formalized. It works at the regional scale, identifying the tendency of river segments to sedimentation, stability, or erosion. The model builds on geomorphologic concepts, and derives its parameters from extensive surveys. As a case study, tendencies of rivers pertaining to the Valle d'Aosta region are analyzed. Some validation is provided both at regional and local scales of analysis. Local validation is performed both through a mathematical model able to simulate the temporal evolution of the stream profile, and through comparison of the prediction with ante and post-event river surveys, where available. Overall results are strongly encouraging. Possible use of the information derived from the model in the context of flood and landslide hazard mitigation is briefly discussed.
\end{abstract}

\section{Introduction}

The identification of flood prone areas is being carried out from the viewpoint of both scientific research and regulations. For many regions, flood maps which identify zones subject to the flooding risk are available. Even though these maps are very important, they represent just a first attempt in the identification of the hazard zones, and some problems related to their use were reported. An improved description of the actual hazard can be obtained, for example, from the availability of maps describing also flow depth and velocity in the flooded area. Besides, it was noticed that cross- section modifications can be induced by the transit of a flood wave, in some cases increasing the hazard level.

Correspondence to: T. Ghizzoni

(tatiana.ghizzoni@cima.unige.it)
On these bases, a mathematical model able to identify zones where river processes are more active is hereinafter proposed. Attention is paid to erosion and sedimentation process at the regional scale, i.e. within an area characterized by homogeneity in its morphological and structural characteristics. Since information availability is of foremost importance in practical use, the need of detailed data about the involved components is avoided.

The model has been tested with reference to the drainage network of the Valle d'Aosta region, Northern Italy (Fig. 1). Streams are therefore identified where the sedimentation process is more active and, as a consequence, the flood hazard tends to increase. By locating the most hazardous zones, it is possible to concentrate the economic resources where they are more urgently needed.

\section{Available information}

Different factors, e.g. climate and morphology, interact in determining the stream network evolution. In particular, climate is the most important solicitation of the system, while morphology is involved in sediment transport. For these reasons a complete study of erosion and sedimentation processes should be based on the knowledge of many components. However, to apply the model in a wide variety of cases - a basic aim of the present work - a simple model is proposed in the following, which needs as few information as possible.

Following Rodriguez-Iturbe (1997), the hydrologic input is described, for each stream, by means of a reference discharge, $Q$, evaluated from the knowledge of the contributing area, $A$, at the specific location along the river network

$Q \propto A^{\alpha}$

Different $\alpha$ values are associated to different reference discharges: $\alpha=1$ describes the mean annual discharge; $\alpha=0.75$ describes a discharge with return time $T=1.5$ years. Since a sort of equilibrium between the most probable annual flood ( $T=1.5$ years) and the long term average channel forms can be assumed (see, e.g., Giannoni et al., 2005), in this work the value $\alpha=0.75$ is used. Moreover, the 0.75 exponent at 


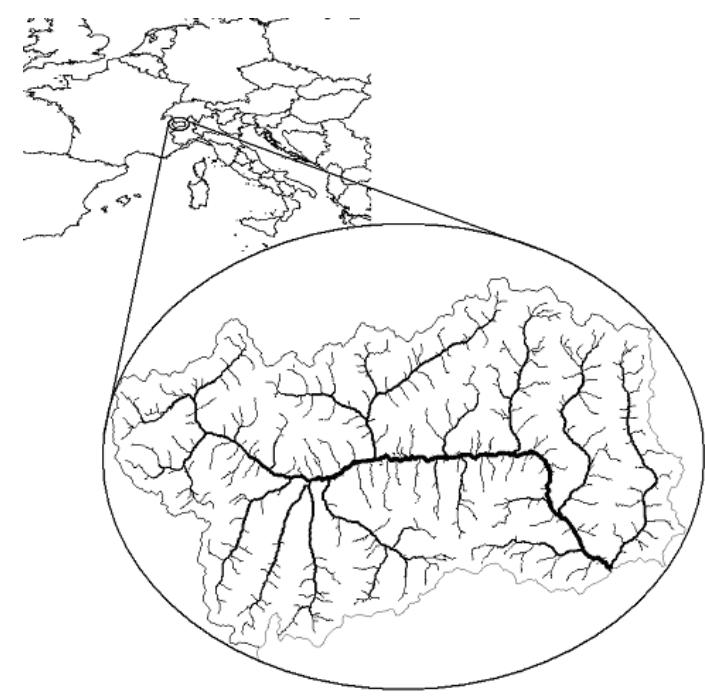

Fig. 1. Location of the Valle d'Aosta Region.

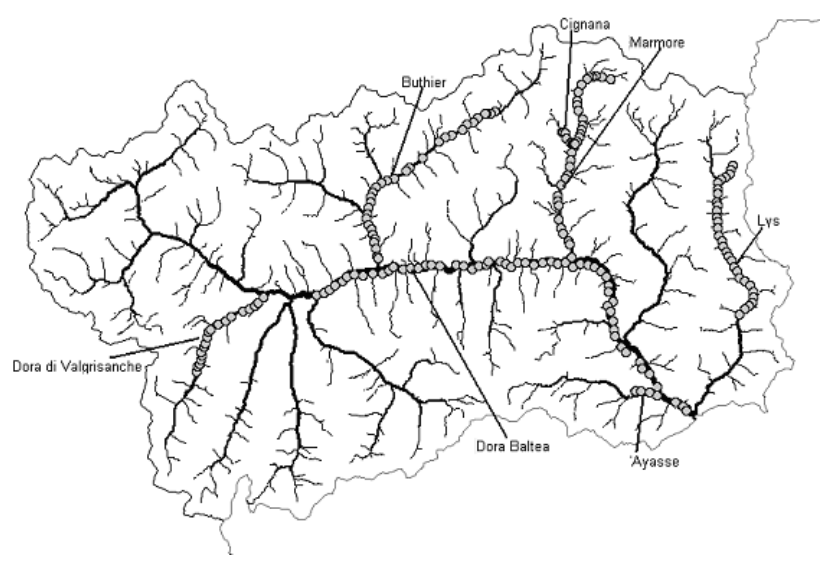

Fig. 2. Dora Baltea River Basin and cross-sections location.

higher flows is a measure of storage in river valleys and a consequence of the fact that rains of high intensity rarely cover the entire basin, but are instead widely and irregularly spaced (Leopold et al., 1964; Rodriguez-Iturbe and Rinaldo, 1997). The increasing of contributing area along the stream network can be obtained from a Digital Elevation Model (DEM) through the identification of drainage directions and the river network. For the present study, the DEM cell size is $25 \times 25 \mathrm{~m}$.

The hydraulic input to sediment motion should be derived from the knowledge of the local depth. Its value depends on the reference discharge, the local slope value, and crosssection characteristics. While the local slope value can be evaluated, with some uncertainty, from the DEM, other relevant cross-section characteristics are only available from surveys. According to the Leopold and Maddock (1953) theory about the geometry of stream channels, the mean flow velocity, $U$, the width of the stream cross-section, $w$, and its depth,

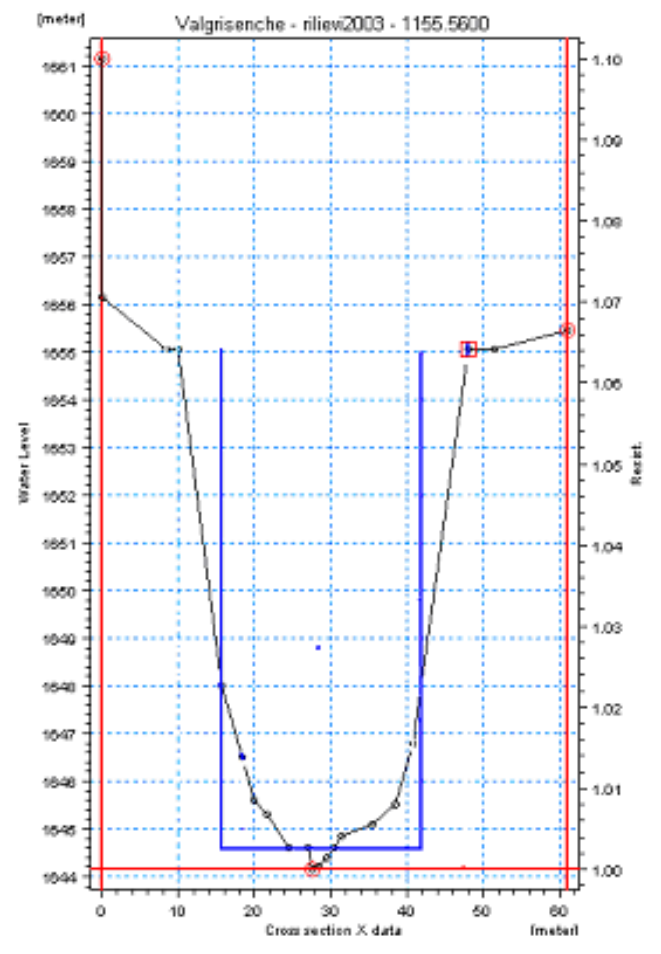

Fig. 3. An example of cross-section data.

$d$, can be related to the reference discharge as

$$
\begin{aligned}
& U \propto Q^{m} \\
& w \propto Q^{b} \\
& d \propto Q^{f}
\end{aligned}
$$

The discharge itself is the product of flow velocity, depth and width. This implies $m+b+f=1$. Through Eq. (1) it is therefore possible to relate these local quantities to drained area.

Relations in Eq. (2) have been calibrated by using available surveys data from the Dora Baltea River and some of its tributaries: Lys, Buthier, Dora di Valgrisanche, and CignanaMarmore (Fig. 2). Since (2) refers to a rectangular geometry of the river cross-section, the shape obtained from surveys data has been simplified accordingly (Fig. 3). In particular, the conversion of actual river sections in rectangular ones is performed by maintaining section area and depth at bankfull discharge conditions. Parameters' values originally proposed by Leopold and Maddock (1953) are confirmed by the analysis of the Val d'Aosta cross-section data as

$b=0.5 \quad f=0.4 \quad m=0.1$

By relating reference discharge to contributing area in the form proposed in (1), and assuming a 1.5 years return time, stream width and depth for Valle d'Aosta are described as

$d=1.5 A^{0.3} \quad w=4.0 A^{3.7}$

\section{Sediment transport}

Erosion and sedimentation processes depend on the stream ability of transporting sediments along the river. Sediment 
discharge can be evaluated by using different approaches. By analyzing the granulometric curve observed in the studied area (pertaining to the Italian Alps) it is possible to note that the convective sediment transport is more important than the dispersive-diffusive mechanism. In this work reference is therefore made to Meyer-Peter and Mueller (1948) equation, written with Einstein's (1950) parameters (Chien, 1954) in the form

$\Phi=8\left(\frac{1}{\psi}-0.047\right)^{\frac{3}{2}}$

with

$\Phi=\frac{q_{S}}{\sqrt{\frac{\rho_{S}-\rho}{\rho} g d_{S}^{3}}}$

$\Psi=\left[\frac{\rho_{S}-\rho}{\rho} \cdot \frac{g d_{S}}{v_{*}^{\prime 2}}\right]$

and $q_{S}$ specific sediment discharge,

$\Psi, \Phi$ Einstein's parameters,

$\rho$ fluid density,

$\rho_{S}$ sediment density,

$g$ gravitational acceleration,

$d_{S}$ sediment diameter,

$v^{\prime} *$ friction velocity caused by surface roughness.

When hydrodynamic conditions allow significant sediment transport, the Shields' parameter is much larger than its critical value, i.e. $1 / \psi>>0.047$. In these cases, sediment discharge can be evaluated as

$q_{S}=\sqrt{\frac{\rho_{S}-\rho}{\rho} g} \cdot 8\left(\frac{\gamma}{\left(\gamma_{S}-\gamma\right)}\right)^{\frac{3}{2}}(R j)^{\frac{3}{2}}$

where $R=w d /(w+2 d)$ is the hydraulic radius, and $j$ the energy level slope. Characteristic values can be introduced in Eq. (7) as

$\rho_{S}=2650 \mathrm{~kg} / \mathrm{m}^{3}$

$\rho=1000 \mathrm{~kg} / \mathrm{m}^{3}$

$g=9.81 \mathrm{~m} / \mathrm{s}^{2}$

$\gamma=9810 \mathrm{~N} / \mathrm{m}^{3}$

$\gamma_{S}=25996 \mathrm{~N} / \mathrm{m}^{3}$

Assuming uniform flow motion (i.e., $j=S$, where $S$ is the local slope) the sediment discharge in flows characterized by large Shields' parameter values (i.e., $1 / \psi>>0.047$ or $R S>>7 \cdot 10^{-4} \mathrm{~m}$ ) can be evaluated as

$q_{S} \cong 15.1(R S)^{\frac{3}{2}}$

\section{The model}

On the basis of mass conservation concepts, a change in riverbed elevation could be expected to be related to sediment discharge balance upstream and downstream of the location under examination. Instability problems, mainly due to difficulties in evaluating the local slope from DEM data, limit a direct application of the equations above introduced in a model based on balance concepts. Conversely, to identify stream elements subject to changes in elevation following flood events, i.e. reaches prone to erosion or sedimentation, it is enough to identify trends, not to provide exact forecast of the drainage evolution. The following procedure is therefore proposed.

1. DEM elevation data are used to obtain a description of the river network, contributing area to each location, $A$, and local slope, $S$;

2. Equation (3) permit the estimation of cross section width, $w$, depth, $d$, and of the hydraulic radius, $R$;

3. If $R S>7 \cdot 10^{-4} \mathrm{~m},(9)$ is used as estimator of the local sediment discharge value, if $R S<7 \cdot 10^{-4} \mathrm{~m}$, sediment transport is null;

4. Unless sediment transport is null, a mass conservation equation is applied between adjacent cells along the drainage direction in the form

$\frac{q_{S}^{\text {in }}-q_{S}^{\text {out }}}{A}=\Delta h$

Due to instability problems, it is not possible to modify the riverbed elevations by using $\Delta \mathrm{h}$ values. For this reason Eq. (10) is used to estimate the tendency to erosion or sedimentation

if $\Delta \mathrm{h}>0$ river bed elevation increases if $\Delta \mathrm{h}<0$ river bed elevation decreases

5. A variation of elevation is applied to locations subject to erosion or sedimentation

if $0.0007 \mathrm{~m}<R S \leq 0.007 \mathrm{~m} \mathrm{DEM} \pm 0.01 \mathrm{~m}$ if $R S>0.007 \mathrm{~m} \mathrm{DEM} \pm 0.05 \mathrm{~m}$

This procedure has been iterated till it was obtained equilibrium between erosion and sedimentation processes, i.e. till most cells were in stability situation. In other words, this procedure has been stopped when the product between hydraulic radius, $R$, and local slope, $S$, was less then $7 \cdot 10^{-4} \mathrm{~m}$ in most cells.

The map of altimetric stream network evolution is finally obtained as the difference between the original DEM and the modified DEM. Results for the Valle d'Aosta region are reported in Fig. 4.

\section{Results and validation}

Results are validated by using two different approaches: the first validation is obtained by comparing model's results, expressed in map format, to the location of alluvial fans reported in the PAI map (a map of the hazardous zones, produced by basin authorities); the second one is based on results obtained from a sediment transport model, developed at the local scale (Lomazzi, 2004). 


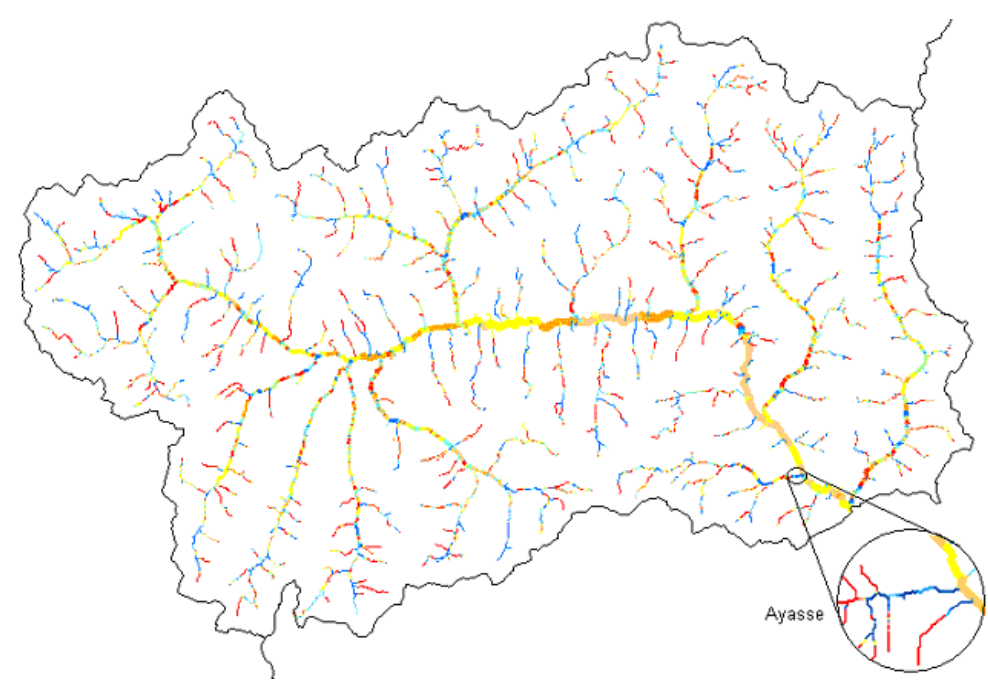

Fig. 4. Altimetric stream network evolution: yellow is stability, red is erosion, and blue is sedimentation.

By analyzing the map of Fig. 4, it is possible to verify that

- zones characterized by sedimentation processes are mainly localized at the end of tributaries, when they reach the valley bottom with a rapid slope reduction;

- zones characterized by erosion processes are localized, on the contrary, in the mountainous part of rivers, where slope is higher;

- the Dora Baltea river is not involved in sedimentation/erosion processes, but it is stable.

By comparing the map of Fig. 4 to the PAI map it is possible to verify that:

- all alluvial fans reported in the PAI map, and mainly localized at the end of Dora Baltea's tributaries, are identified by the presented model;

- 90\% of smaller alluvial fans, localized in the mountainous part of the rivers, are identified by the model;

- some reaches, mapped by this model as prone to sedimentation processes, are not identified by the PAI map as alluvial fans. It would be very interesting to study them in detail to verify the reliability of the presented model.

The second approach used to validate the results is based on a sediment transport model developed at the local scale (Lomazzi, 2004). This, differently from the regional scale model, estimates the altimetric evolution of a reach by precisely evaluating the bed level variation according to MeyerPeter and Mueller sediment transport theory plus a simple balance concept. The model has been tested on a reach where the variations produced by a flood event were known. In this case, ante and post-event surveys were available. Another peculiarity of the chosen segment is that the banks cannot be modified by the flood: this allows modeling only bottom level variations, without considering width changes.
The final segment of the Ayasse river, a tributary of Dora Baltea, has been analyzed as modified by the flood event occurred in Northern Italy on 13-15 October 2000. Available surveys divide this $420 \mathrm{~m}$ segment in 14 cross sections, whose shape has been simplified to rectangular geometry. Upstream and downstream boundary sections, located on two large weirs, were not changed during the flood event. Accordingly, boundary conditions are set to produce no variations in elevation.

The flood discharge has been estimated by means of the DRiFt semi-distributed rainfall-runoff model (Giannoni et al., 2005). The rainfall input is provided from two rain gauges: Champorcher-Chardonnay, located approximately in the center of the Ayasse basin, and Donnas-Clapey, $3 \mathrm{~km}$ downstream of the confluence with Dora Baltea River. Rainfall data have been considered from 1 September to 16 October. The rainfall-runoff model also requires temperature and solar radiation data to evaluate the soil moisture conditions before the flood event. The hydrograph produced by DRiFt presents a total volume of $17.9 \times 10^{6} \mathrm{~m}^{3}$ and an average discharge of $93 \mathrm{~m}^{3} / \mathrm{s}$; this value is assumed as the discharge input for the evaluation of the evolution in time of the reach under exam.

Through the HEC-RAS hydraulic software, it has been verified that 1) both ante and post-event bottom profile implies for all cross-sections a depth which is always lower than the critical depth, 2) the maximum depth of the Dora Baltea river at the confluence with Ayasse River during the flood event $(8.73 \mathrm{~m})$ does not perturb the stream in the analyzed reach. Therefore, steady supercritical flow conditions are assumed for the simulation.

Hydraulic data have been used as input to Meyer-Peter and Mueller theory (4), to evaluate sediment discharge: in particular, from the granulometric curve observed in the analyzed reach, sediment diameter value can be estimated as $d_{s}=0.02 \mathrm{~m}$. The total sediment load for the section, $Q_{s}$, is

$Q_{s}=q_{s} \cdot w$ 
Table 1. Ante and post-event bed elevation, simulation results and their difference.

\begin{tabular}{|c|c|c|c|c|c|}
\hline & \multicolumn{3}{|c|}{ LEVEL $[\mathrm{m}]$} & \multicolumn{2}{c|}{ DIFFERENCES [m] } \\
\hline sezioni & ante & post & simulation & post-ante & simulation-post \\
\hline 34 & 364,2 & 364,2 & 364,2 & 0 & 0 \\
\hline 33 & 363 & 363,3 & 363,2 & 0,3 & $-0,1$ \\
\hline 32 & 362,2 & 362,5 & 362,3 & 0,3 & $-0,2$ \\
\hline 31 & 360,3 & 361,5 & 361,6 & 1,2 & 0,1 \\
\hline 30 & 359,2 & 361 & 360,3 & 1,8 & $-0,7$ \\
\hline $29 \mathrm{~b}$ & 359 & 359,4 & 359,3 & 0,4 & $-0,1$ \\
\hline 28 & 356 & 356,7 & 357 & 0,7 & 0,3 \\
\hline 26 & 354,2 & 354,4 & 354,7 & 0,2 & 0,3 \\
\hline $25 \mathrm{~b}$ & 352,4 & 354,1 & 354,5 & 1,7 & 0,4 \\
\hline 24 & 352 & 352,7 & 353,2 & 0,7 & 0,5 \\
\hline 22 & 351,2 & 351,7 & 352 & 0,5 & 0,3 \\
\hline 21 & 350,2 & 351,3 & 351,1 & 1,1 & $-0,2$ \\
\hline 20 & 349,1 & 350,5 & 350,4 & 1,4 & $-0,1$ \\
\hline 19 & 349,1 & 349,1 & 349,1 & 0 & 0 \\
\hline
\end{tabular}

Bed level variations have been estimated by imposing mass balance for every cell (cell surface is a function of cross-section size). Mass balance implies that the level variation in the downstream cell, $\Delta z_{D}$, is evaluated as

$\Delta z_{D}=\frac{Q_{s, U}-Q_{s, D}}{S_{D}} \Delta t$

where

$Q_{s, U}=Q_{s}$ in the upstream cell $\left[\mathrm{m}^{3} / \mathrm{s}\right]$

$Q_{s, D}=Q_{s}$ in the downstream cell $\left[\mathrm{m}^{3} / \mathrm{s}\right]$

$S_{D}$ is surface of downstream cell $\left[\mathrm{m}^{2}\right]$

$\Delta t$ is the time step of the model [s].

Updated bed level is evaluated by adding $\Delta z_{D}$ to the former value. The new river bottom level is the input to evaluate the new stream depth, which causes different $Q_{s}$, and then a new level variation. This procedure has been iterated for the length of flood event, 54 hours. The time step must be short enough to avoid instability problems. In this case it has been assumed equal to $60 \mathrm{~s}$.

Table 1 shows ante and post-event measured bed elevation, simulation results, and their difference.

Despite model simplicity, results are close to reality. For almost all sections, model errors are equal or less than $0.3 \mathrm{~m}$. The bigger error is an underestimation of $0.7 \mathrm{~m}$, in a section (30) characterized by an increase of $1.8 \mathrm{~m}$. In cross-sections $25 \mathrm{~b}$ and 24 errors are respectively 0.4 and $0.5 \mathrm{~m}$. These sections are located on a segment of the reach with many weirs that cause perturbations to the flow. Model results and survey data are also reported in Fig. 5. It is possible to notice how the model simulates quite correctly the trend of post-event bottom profile. The only exception is the cross-section 30 , for which the simulated profile is more rectilinear then real post-event profile.

Model results and river surveys indicate a reach prone to sedimentation process. The regional scale model identifies this reach as an alluvial fan, too. So the results of the regional scale model are confirmed by both the local scale one and by river surveys.

\section{Conclusions}

The regional scale model is able to identify, at the regional scale, streams where erosion and sedimentation processes are

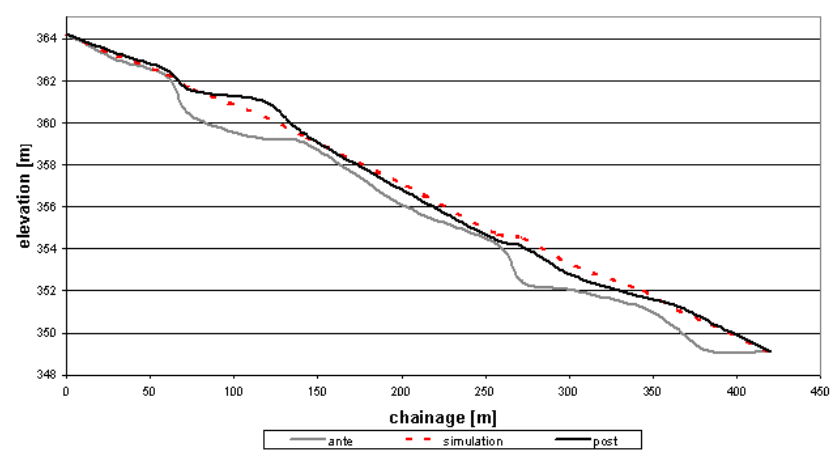

Fig. 5. Ante-event, post-event and simulated river bottom profiles.

more active. Processes of sedimentation during flood events, by reducing the river cross section, are likely to increase the flooding risk in these streams.

The identification of reaches in which the sedimentation process prevails is a first step for the development of further investigation, to be performed at the local scale, needed to confirm or reject regional scale results. From this viewpoint, the model is a useful tool to concentrate economic resources in flood prone areas.

Edited by: V. Kotroni and K. Lagouvardos

Reviewed by: anonymous referee

\section{References}

Chien, N.: Meyer-Peter formula for bed-load transport and Einstein bed-load function, University of California Institute of Engineering Research, Berkeley, California, 1954.

Einstein, H. A.: The bed load function for sediment transportation in open channel flows, Tech. Bull., 1026, 78 pp., U.S. Dep. of Agric., Soil Conserv. Serv., Washington, D.C., 1950.

Giannoni, F., Roth, G., and Rudari, R.: A procedure for drainage network identification from geomorphology and its application to the prediction of the hydrologic response, Adv. Water Res., 28 (6), 567-581, 2005.

Leopold, L. B. and Maddock Jr., T.: The hydraulic geometry of stream channels and some physiographic implications, U.S. Geological Survey professional paper, 282-A, Washington, D.C, 1953.

Leopold, L. B., Wolman, M.G., and Miller, J. P.: Fluvial Process in Geomorphology, Freeman, San Francisco, 1964.

Lomazzi, M.: Analisi a scala locale delle tendenze evolutive dei corsi d'acqua montani - Applicazione al torrente Ayasse, Valle d'Aosta - University of Genoa, Italy, 2004.

Meyer-Peter, E. and Mueller, R.: Formulas for bed load transport, paper presented at 2nd Meeting IAHR, Int. Assoc. Hydraul. Res., Stockholm, 1945.

Rodriguez Iturbe, I. and Rinaldo, A.: Fractal river basins - Chance and self-organization, Cambridge University Press, New York, 1997.

Shields, A.: Anwendung der Ähnlichkeitsmechanick und Turbulenz-forschung auf die Geschiebebewegung, Mitt. Preuss. Versuchsanst. Wasser, Erd, Schiffsabau, Berlin, 1936. 